\title{
Immersive Deep Maps for Inaccessible Heritage Sites
}

\author{
Alisa Pettitt \\ Fairfax County Park Authority, Alisa.Pettitt@fairfaxcounty.gov
}

Keywords: Immersive Virtual Reality (IVR), Deep Map, Archaeology, Sense of Presence

\begin{abstract}
:
The Covid-19 pandemic temporarily shut down countless museums and suspended archaeological excavations on an international level. These closures barred scientists and the public from significant heritage sites and collections. To remedy this inaccessibility issue, many institutions turned to digital platforms, connecting with communities through virtual talks and tours of their physically closed spaces. These virtual programs, experienced over desktop or mobile devices, provided a means of investigating unreachable places but were unable to replicate the sensation of being present at a heritage site.
\end{abstract}

Immersive deep maps experienced through commercially available virtual reality systems e.g., Oculus Rift, offer users the sensation of being in another place. In immersive virtual environments (IVE), the user explores information through a virtual avatar, visiting representations of inaccessible places, closely inspecting data such as artefact models, and even walking through different temporal periods at heritage sites. In IVEs, users sense they are present within these environments, a phenomenon known as sense of presence. Users achieve a heightened sense of presence in immersive spaces when they feel a) they are in control of their experience, b) the IVE stimulates their senses c) the space is realistic, and d) real-world distractions are limited (Witmer and Singer 1998).

This research details the development of an immersive deep map exhibit for virtually transporting users to Clark's Branch, a pre-European contact heritage site outside Washington D.C. The exhibit combines realistic terrain, flora, fauna, and artefact models, soundscapes, and narrative developed with assistance from descendants of the region's indigenous people and archaeological experts. In the exhibit, users virtually walk through lifelike digital reconstructions of Clark's Branch and travel through time at the site by moving through virtual portals (Figure 1). The portals link interpretations of the site's different temporal periods and serve as main components of the exhibit's wayfinding system, helping users orient themselves in space and time. The Clark's Branch deep map exhibit was developed in Unity, a real-time development platform, and presented through an Oculus Rift head-mounted display (HMD).

In addition to virtually transporting users to Clark's Branch, this work aimed to improve users' knowledge of Clark's Branch through a deep mapping framework. A deep map is a Spatial Humanities term for a dynamic map that functions as a repository for various types of tangible, i.e. artifacts and architectural ruins, and intangible, i.e., linguistics and belief systems, data (Early-Spandoni 2017). The Clark's Branch deep map exhibit connects different types of multidimensional cultural, environmental, and spatiotemporal information, inviting the user to explore site data through an immersive first-person perspective.

To determine if exhibit users felt the immersive deep mapping framework expanded their understanding of complex components linked to Clark's Branch, both archaeologists and non-specialists explored the exhibit and provided feedback through questionnaires and a focus group discussion. The findings of this study suggest that exhibit users experienced a sense of presence and believed the immersive deep mapping framework enhanced their knowledge of Clark's Branch. The archaeologists that participated in the study remarked on the exhibits use beyond virtual access from training junior scientists, exploring environmental factors no longer at sites, and studying artefacts and archaeological features in situ. Additionally, several exhibit users indicated the immersive experience helped them build personal connections to past peoples. The results of this study suggest that immersive deep map exhibits connect archaeologists and public audiences with history through the sense of being in another place, offering a virtual solution to exploring sometimes-inaccessible heritage sites. 


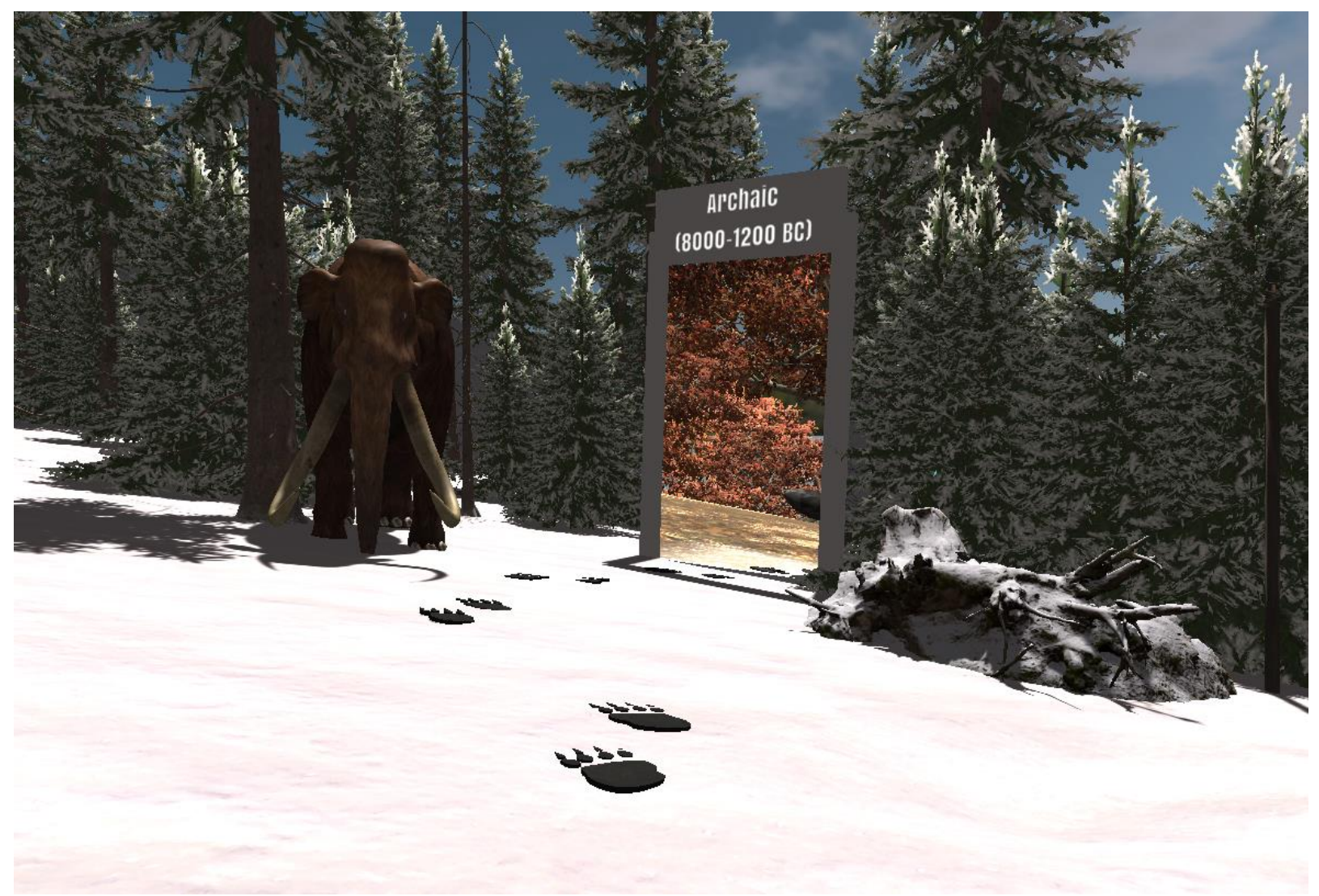

Figure 1. The Paleoindian Period and Archaic Portal in the Clark's Branch Immersive Deep Map Exhibit

\section{References}

Earley-Spadoni, T., 2017. Spatial History, deep mapping and digital storytelling: Archaeology's future imagined through an engagement with the Digital Humanities. Journal of Archaeological Science, Vol. 84, pp. 95-102.

Witmer, B.G., and Singer, M.J. Singer, 1998. Measuring Presence in Virtual Environments: A Presence Questionnaire In: Presence: Teleoperators and Virtual Environments Vol. 7, pp. 225-40 